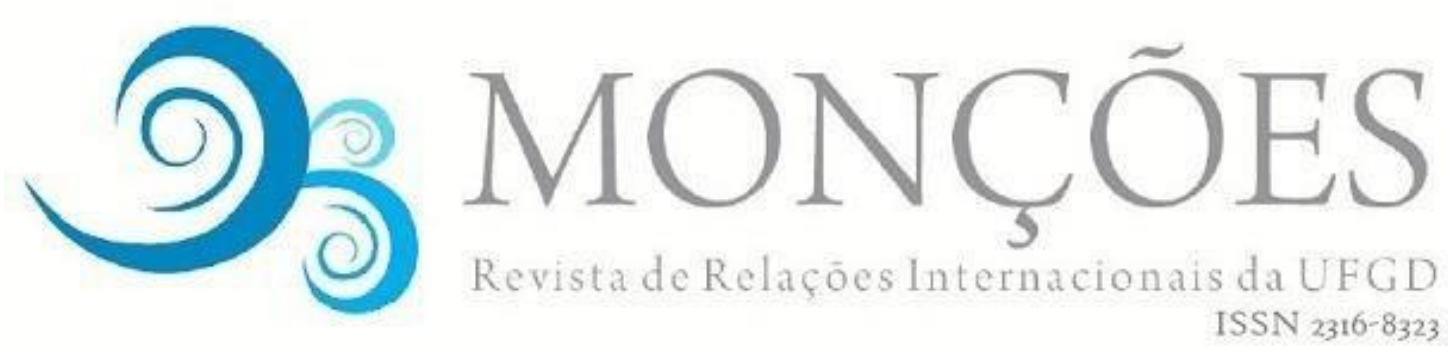

\title{
LIMITES E FRONTEIRAS NA ÁFRICA AUSTRAL: MOÇAMBIQUE E PROCESSO DE DELIMITAÇÃO E DESAFIOS DA REAFIRMAÇÃO FRONTEIRIÇA NA REGIÃO
}

EMÍLIO JOVANDO ZECA

Doutorando do Programa de Pós-Graduação em Estudos Estratégicos Internacionais na UFRGS, Investigador do Departamento de Paz e Segurança do Centro de Estudos

Estratégicos e Internacionais - CEEl/ISRI de Moçambique.

RESUMO: O presente artigo tem como objetivo central refletir sobre o processo de delimitação dos limites e fronteiras de Moçambique, na região da África Austral bem como os desafios contemporâneos da necessidade de reafirmação das fronteiras enfrentados pelo país. Partindo de uma metodologia qualitativa assente na observção direta, método histórico e técnica documental, o estudo constata que não obstante ao fato de Moçambique ter alcançado sua independência em 1975, ainda existem vários pontos onde a delimitação de fronteira não é definitiva, abrindo espaço para conflitos e disputas fronteiriças com Estados vizinhos. Desta feita, o Estado tem que ter sempre presente as ambições e necessidades territoriais dos vizinhos, com vista a salvaguardar os limites e as fronteiras herdadas na época da independência. Portanto, há necessidade de reafirmação das fronteiras tendo em conta as orientações da União Africana.

Palavras-Chave: Limites; Fronteira; Delimitação de Fronteira; Reafirmação de Fronteira.

\section{LIMITS AND BORDERS IN SOUTHERN AFRICA: MOZAMBIQUE AND THE CHALLENGES OF DELIMITATION AND REAFFIRMATION BORDER PROCESS IN THE REGION}

\begin{abstract}
The present article reflects on the process of delimiting borders in Mozambique and Southern African region. Also it focuses in the contemporary challenges that Southern African countries face to reaffirm their borders. Based on a qualitative methodology, direct observation, historical method and documentary technical, the study notes that nevertheless Mozambique acquired its independence in 1975, there are still several points where border delimitation is not yet definitive, opening spaces for borders conflicts and disputes with neighboring states. Thus, Mozambique and other Southern Africa countries must be attentive with territorial ambitions of their neighbors to safeguarding its limits and as inherited frontiers of independence time. Therefore, it is necessary the reaffirmation of borders process according to the African Union guidelines.
\end{abstract}

Keywords: Limits; Border; Border Delimitation; Border Reaffirmation. 


\section{Introdução}

O presente trabalho faz uma análise dos contornos em volta do processo de delimitação de fronteiras na região da África Austral, com destaque para os limites e fronteiras de Moçambique. O estudo centra-se nos processos e conflitos por detrás da sua delimitação fronteiriça, no período colonial e os principais desafios atuais centrados, basicamente, na necessidade de reafirmação dos limites e fronteiras, tendo em conta as orientações da União Africana - princípio utti possidetis, uti possidetis iuris conhecido como intangibilidade das fronteiras - e as situações de deslocações de marcos fronteiriços, por motivos naturais ou ações antropomórficas deliberadas por parte dos Estados com ambições e necessidades de expsanção terrotorial, com destaque para Malaui.

A fronteira é um fenómeno ligado ao Estado moderno que foi inventado, na Europa, entre os séculos XIII-XV, com a "função inicial de definir a distribuição de áreas entre Estados territoriais" (CARNEIRO, 2016, p. 20). Esta função foi alargada para outros domínios, com destaque para função legal - delimitação do território nacional onde prevalecem as instituições jurídicas que regem o Estado e a sociedade; função fiscal - defesa do mercado interno de uma unidade política; e função de controle - vigiar pessoas e bens que cruzam o território (GUICHONNET e RAFFESTIN, 1974, p. 224 ${ }^{1}$, citados por CARNEIRO, 2016, p. 22).

Desta feita, trata-se de um mecanismos encontrados para demarcar 0 espaço e o território sobre o qual deveria ser exercício do poder de uma unidade política. Desta feita, a fronteira passou a ser um elemento de delimitação entre o espaço nacional e o exterior da referida unidade política, o que lhe dá um estatuto de demarcador de espaços de exercício de poder, que pode ser entendido como limite. Todavia, de acordo com Machado (1998), as fronteiras e limites são dois termos com sentidos e significados diferentes:

A fronteira está orientada "para fora" - forças centrífugas - enquanto
os limites estão orientados "para dentro" - forças centrípetas. Enquanto
a fronteira é considerada uma fonte de perigo ou ameaça, porque pode
desenvolver interesses distintos aos do governo central, o limite
jurídico do Estado é criado e mantido pelo governo central, não tendo

${ }^{1}$ GUICHONNET, P. e RAFFESTIN, C. Géographie des Frontières. Paris : Presses Universitaires de France, 1974. 
vida própria e nem mesmo existência material - é um polígono (MACHADO, 1998, p. 3).

Em termos práticos, pode-se depreender que o limite transmite a ideia de uma linha separadora, enquanto fronteira a de uma faixa, o que implica a existência de uma área. Todavia, existe um ponto de convergência entre fronteira e limite que é o fato dos dois fenómenos serem mecanismos de separação entre entidades, numa determinada extensão. Desta feita, como pontua Carneiro (2016, p. 21), "as faixas territoriais de cada lado do limite internacional [de cada Estado] compõem a zona de fronteira"2.

As fronteiras e os limites são elementos essenciais para a existência do Estado. Em relação a esse ponto, "o Estado não é consebível sem território e sem fronteiras" (RATZEL, 1983, p. 93). Na perspetiva do autor, o Estado não pode existir sem um solo, entendido como território. Desta feita, esse território, enquanto unidade política, tem limites e fronteiras. Portanto, os limites dessa unidade política serão as faixas territorias de cada lado internacional, enquanto a fronteira tem que ver com a área territorial da unidade política e os limites com os outros Estados, que dá a ideia de delimitação territorial e política e que é equivalente à soberana, na tradicional teoria de Estado e direito.

Pala ilustrar os limites e fronteiras de Moçambique, foram produzidos dois mapas, com recurso ao Programa Informático ArcGis. A produção cartográfica foi levada a cabo no Laboratório de Sensoriamento Remoto Geológico do Centro Estadual de Pesquisas em Sensoriamento Remoto e Meteorologia, na Universidade Federal do Rio Grande do Sul - UFRGS, em Porto Alegre, com apoio e supervisão do Prof. Dr. Camilo Carneiro³ , em Dezembro de 2016.

\footnotetext{
${ }^{2}$ Alguns países estipulam em lei a extensão de suas faixas de fronteira, que em alguns casos possuemuma regulação especial, diferente do restante do território nacional (CARNEIRO, 2016, p. 21).

${ }^{3}$ Autor da obra "Fronteiras Irmãs: Transfronteirizações na Bacia do Prata" (2016), Camilo Carneiro é Professor do Curso de Relações Internacionais na Escola Superior de Propaganda e Marketing - ESPM; Pós-doutorado e professor colaborador do Programa de Pós-Graduação em Estudos Estratégicos Internacionais da UFRGS - PPGEE//UFRGS; pesquis ador do grupo de pesquisa LABETER - Laboratório Estado e Território da UFRGS; Doutor em Geografia pela Universidade Federal do Rio Grande do Sul; Doutorado sanduíche pela Universidade Paris 1, Panthéon-Sorbonne; Mestre em Geografia pela Universidade Federal do Rio de Janeiro; possuigraduação em Geografia e Meio Ambiente pela Pontifícia Universidade Católica do Rio de Janeiro e graduação em Bacharelato em Direito pela Pontifícia Universidade Católica do Rio de Janeiro; tem experiência na área de Geociências, comênfase em Geografia Política e Cartografia.
} 
Baseando-se numa metodologia qualitativa, assente no método histórico, observação direta e pesquisa bibliográfica, o trabalho está estruturado em quatro sessões, antecedidas da introdução e seguidos das considerações finais e referências bibliográficas. A primeira apresenta a situação dos limites e fronteiras na África Austral précolonial e colonial, desde as expansões bantu até a Conferência de Berlim de 1885. A segunda sessão sistematiza as principais disputas e acordos que culminaram com a delimitação de limites e fronteiras de Moçambique, com destaque para os acordo firmados entre Portugal e Inglaterra. A última sessão apresenta os desafios contemporâneos da reafirmação das fronteiras moçambicanas.

\section{Limites e Fronteiras na Região da África Austral Pré-Colonial e Colonial}

A região da África Austral fica localizada na zona sul do continente africano e é composta por Estado como que foram colónias europeias, desde o Século XV. O Império Colonial Português teve o controlo de Angola e Moçambique; o britânico da África do Sul, Lesotho, Suazilândia, Botswana, Malaui, Zâmbia e Zimbábue; o francês controlou a zona insular, com destaque para Madagáscar, Seychelles e Maurícias; o alemão a Tanzânia e Namíbia - Sudoeste Africano e o holandês a Província do Cabo, na África do Sul. Todavia, as fronteiras précolonias, na região da África Austral, eram caraterizadas por, um lado, por uma continuidade em termos de grupo etnolonguístico - dominado pelos povos bantu - mas por outro, por uma descontinuidade étnica e sociocultural. Em relação as descontinuidades socioculturais, de acordo com Rosière $(2007)^{4}$ citado por Carneiro, (2016, p. 22)

As fronteiras socioculturais são descontinuidades maiores de natureza econômica ou étnica, às vezes no espaço - a paisagem - e geralmente sensíveis de um ponto de vista político. No entanto, os limites entre duas áreas socioculturais diferentes - de um ponto de vista linguístico, confessional ou socioeconômico - nem sempre é claro, sendo a evolução espacial dos idiomas um caso especial. As fronteiras linguísticas são objetos difíceis de entender,poisas línguas podem evoluir ou se sobrepor, haja vista que elas não são objetos claros, cujo falantes ocupam um território com a exclusão de qualquer outro (ROSIÈRE, 2007, p. 426).

\footnotetext{
${ }^{4}$ ROSIÈRE, Stéphane. Géographie Politique et Géopolitique : Une Grammaire de L'Espace Politique. Paris : Elipses, 2007.
} 
O povo bantu, enquanto grupo etnolinguísitico, é composto por mais de 400 grupos étnicos que possum uma mesma raíz linguística materna. Enquanto a raíz linguistica constitui um elemento de continuidade, as peculiaridades étnicas constituem elementos de descontinuidade, uma vez que há algumas especificidades na estrutra social,política e econonômica de cada grupo. Há um ponto de convergência de que o povo bantu trata-se de um grupo com uma base etnolínguistica comum - caraterísticas fonológicas e morfológicas do conjunto de palavras - e que "cedo se tornou num termo aplicado indiscriminadamente a raça, lultura e língua" (HALL, 1987, p. 161).

\section{Mapa 1: Expansão do Povo Bantu}

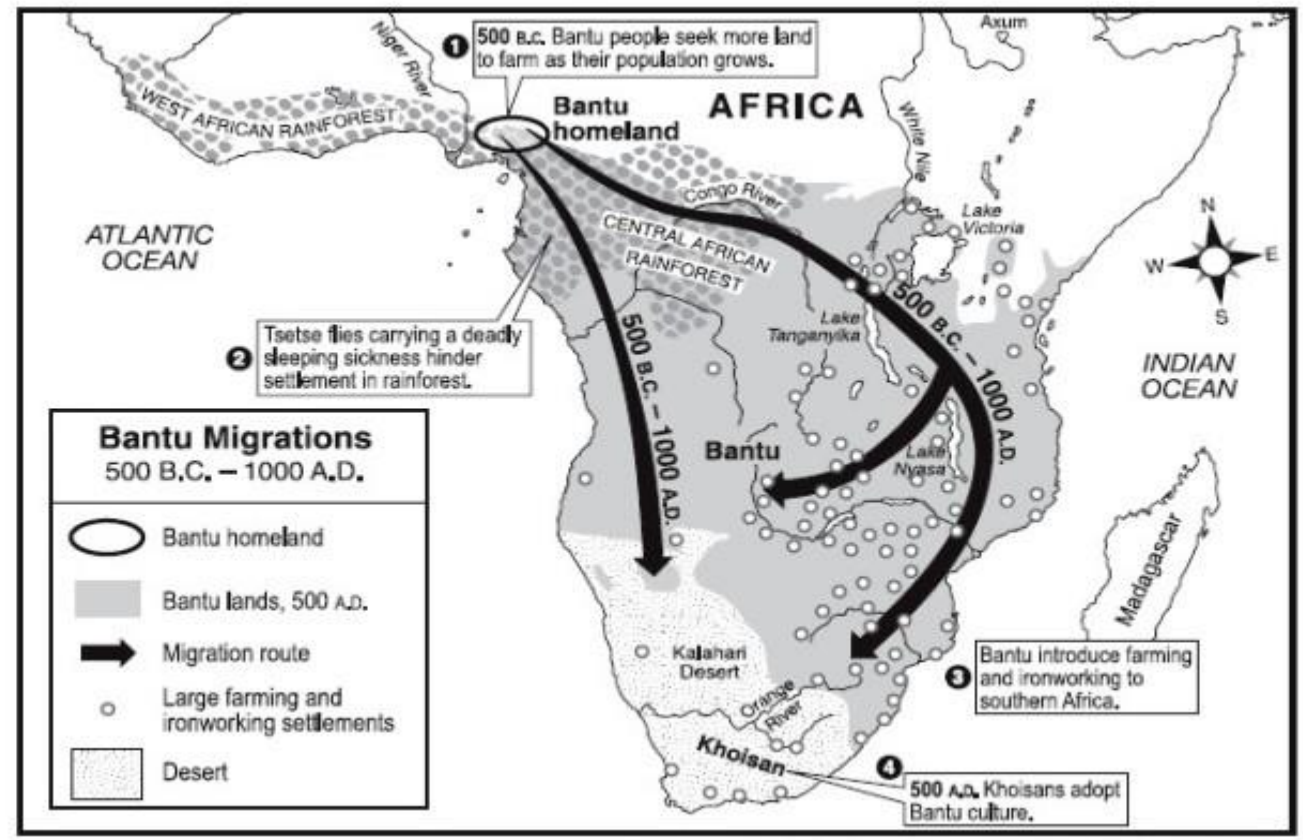

Fonte: Jones (2012, p. 56)

O mapa 1, acima, ilustra o processo de expansão, através de processos migratórios contínuos e descontínuos do povo bantu que se instalaram na região austral de África, no período compreendido entre 400 a.C. e 1000 d.C. Eles povoaram a região austral de África, vindo da região dos Grandes Lagos ${ }^{5}$

\footnotetext{
${ }^{5}$ A problemática da expansão dos bantus foi motivo de vários estudos, mas não há consenso entre a origem e dinâmica migratória, mas sim que instalaram-se na África Austral. Joseph Greenberg apresentou a ideia de que a migração se deu em direção ao sul, a partir da zona de fronteira entre os Camarões e Nigéria. Malcolm Guthrie defendeu a ideia de que o centro da expansão bantu foi a região de Luba, na Província de Shaba, no Congo. Roland Oliver defendeu que as duas posições assumidas por Greenberg e Guthrie são complementares, correspondendo a diversas fases diferentes. David Phillips on defendeu, mais tarde, que a
} 
Florestas dos Camarões, Nigéria ou Luba na Província de Shaba - no Congo, por volta de 2000 a.C. A ocupação dos territórios pelo bantu, na região autral de África não seguiu critérios de limites e fronteiras do Estado Moderno, mas sim um processo de ocupação natural dos espaços, instalando-se de forma livre nesses territórios, onde passaram a desenvolver um conjunto de atividades relacionadas com "domesticação de plantas e animais e trabalho com cerâmica, ferro, agricultura e pastorícia" (HALL, 19987 p. 26-27), fruto de transformações nas relações sociais e climáticas, depois da sua instalação nestes territórios.

Depois da instalação dos povos bantu, na África Austral, os limites e fronteiras foram estabelecidas tendo em conta os grupos étnicos, numa clara alusão às fronteiras socioculturais de Rosière (2007, p. 426). Todavia, esse mapa fronteiriço muda drasticamente com a intervenção de potências colonizadoras, na região, sobretudo depois da Conferência de Berlim (1884$1985)^{6}$. Este evento instalou um novo modelo de limites e fronteiras, em África, trazendo o modelo europeu para o continente negro

A istalação do modelo europeu de limites interestatais rígidos remonta à "Conferência de Berlim" de 1885, quando as potências europeias e mais os Estados unidos resolveram escolher critérios mínimos que fossem aceitos para todos os que disputavam "a partilha da África" (MARTINS, 1997, p. 79).

A partilha de África, na Conferência de Berlim, foi um momento de disputas das grandes potências, sobre quem ficaria com maiores porções do continente como sua zonan estratégicas e de influência. Todavia, o processo de delimitação de limites e fronteirass não seguiu as fronteiras socioculturais estabelecidas na região, não respeitando as etnicas, tradições e culturas dos povos préestabelecidos. Devido aos interesses das potências europeias, "povos com a mesma identidade foram separados; etnias rivais foram reunidas; e linhas tradicionais de comércio foram interrompidas por barreiras aduaneiras" 7

origem da expansão bantu, encontra-se nas Florestas dos Camarões, tendo havido dois movimentos: um que contornou a floresta em direção dos Lagos - a oriente - e outro que o seguiu atravessando a floresta em direção ao Congo e Angola. Christopher Ehret apoiou a posição de Greenberg, baseando o seu estudo na distribuição e características fenológicas e morfológicas das palavras nas línguas bantu (SOUTO, 1995, p. 26).

6 "Quanto às fronteiras, a principal deliberação [da Conferência de Berlim] rezava que, a partir daquele momento, a ocupação da costa não seria mais considerada suficiente para a reivindicação do interior correspondente a menos que esse fosse ocupado de maneira efetiva" (MARTINS, 1997, p. 79-80).

${ }^{7}$ Apenas para citar alguns exemplos: fulanis entre Nigéria e Camarões; hausas entre Nigéria e Níger; iorubas entre Nigéria e Benim; mandingas entre Libéria, Guiné Bissau e Senegal; os bacongoe bulundá 
(MARTINS, 1997, p. 80). As rivalidades inter-étnicas e tribais estiveram sempre ao serviços dos interesses europeus e foram por eles insentivados - princípio de dividir para reinar.

Como resultado deste processo, os limites e fronteiras, em África, resultaram de operações de "lapís, esquadro e compasso", nas mesas de reuniões da Conferência de Berlim. Tratam-se de limites artificiais que não respeitaram os principios étnicos, sociais e culturais dos povos da região. Todavia, como nem sempre era possível conciliar os interesses das potências europeias nesse domínio, surgiram conflitos de delimitação fronteiriça, por um lado, e as dificuldades de materializar o princípio de ocupação efectiva, por outro. Diante deste cenários, a mediação ${ }^{8}$, arbitragem ${ }^{9}$ e assinatura de acordos e tratados de de delimitação fronteiriça foram as saídas encontradas ou ameaça de uso da força. É neste contexto, que abaixo, se apresenta as principais disputas de delimitação de fronteiras e limites envolvendo Portugal e outras potências e que culminaram na atual configuração fronteirça de Moçambique.

Com o alcance das independências de Estados africanos, na década de 1960, a Organização da Unidade Africa, organização antecessora da União africana, no Artigo 3 da carta da sua constituição de $1963^{10}$ estabeleceu como princípios a igualdade soberana entre todos os Estados membros; a não ingerência nos assuntos internos de outros Estados; respeito pela soberania e integridade territorial de cada Estado e o direito inalienável a existência; e a resolução pacífica de disputas pela negociação, mediação, conciliação e outros métodos. A defesa da integridade territorial dos Estados independentes nos moldes alcançados dos antigos colonizadores foi uma preocupação

estravasaram as fronteiras do Congo e Angola; eritreus e somalis lutaram contra etíopes e como resultado, Etiópia perdeu o acesso ao mar; os ewe foram dispersos pelo Ghana, Togo e Benin; agudizaram as rivalidades entre malinkes e fulas, na Guiné; changanas foram separados entre África do Sul e Moçambique; Yaos entre Malaui, Moçambique e Tanzânia. Esta configuração proporcionou situações de revindicações secessionistas: Katanga, Biafra, Cabinda, entre outros casos.

${ }^{8}$ A mediação é um processo de prevenção, gestão e resolução de conflitos no qual a Terceira Parte ajudar as partes em conflito a dialogar e cooperar para ultrapassar suas diferenças. Trata-se de um processo voluntário que depende da vontade política e cometimento das partes. O mediador dever ser uma figura pública, caris mática, idónea, respeitada e de confiança das partes em conflito (ZECA, 2013, p. 48-49).

${ }^{9}$ A arbitragem é considerada a forma mais antiga e comum de resolução de conflitos através de uma terceira parte - árbitro - onde as partes escolhem um árbitro ou um tribunal com poder real e de facto para dirimir o caso. No processo de arbitragem, cada parte apresenta sua posição para o árbitro, que estabelece regras a respeito das questões - decisão do árbitro deve ser cumprida (ZECA, 2013, p. 50).

${ }^{10} \mathrm{O}$ artigo 4 do Ato Constitutivo da União Africana (2000) reitera os princípios aqui apresentados. 
fundamental. Pretendia-se com isso eliminar as condições para a eclosão de conflitos e posterior desintegração dos Estados, pois seriam muitos a revindicarem territórios para integrá-los noutros, ou o aparecimento de vários pequenos Estados estabelecidos nos antigos reinos africanos, tais como os loruba, Congo, Império de Gaza, Zimbábue, entre outros, como foi referido, anteriormente. Vários povos tinham sido repartidos pelas potências europeias, como forma de facilitar o processo de colonização.

\begin{abstract}
O problema multiétnico vem do tempo colonial, quando as fronteiras foram desenhadas artificialmente e a heterogeneidade tornou-se um padrão. O resultado desta situação é que nação homogénea ou Estado monoétnico, em África, tais como a maioria dos históricos Estados précoloniais que sobreviveram com as suas fronteiras originais mais ou menos intatas, tornaram-se numa exceção à regra" (BREYTENBCH, 2002, p. 87).
\end{abstract}

Os princípios de não ingerência nos assuntos internos de outros Estados e do respeito pela soberania e integridade territorial foram sempre violados, de forma sistemática, devido as ambições territoriais de muitos Estados africanos, consubstanciadas pelas ambições políticas de muitas lideranças políticas. A questão do respeito pela intangibilidade das fronteiras não foi respeitada em vários casos. Neste aspeto, a Organização da Unidade Africana e a sua sucessora União Africa, bem como as organizações de integração regional africanas mostraram-se incapazes de fazer valer as posições e princípios estruturantes da relação entre os Estados membros da organização. Na maioria dos casos, a posição do Estado mais forte política, económica e militarmente e as influências estrangeiras veio ao de cima, impedindo uma tomada de posição firme das organizações contra o Estado que levou a cabo a mudança de fronteiriças e limítrofes entre os Estados.

\title{
Disputas e Delimitação de Limites e Fronteiras de Moçambique
}

As disputas para a configuração atual das fronteiras de Moçambique envolveu Portugal, Inglaterra e Alemanha, tendo como pano de fundo a necessidade da "ocupação efetiva" determinada pela Conferência de Berlim, no Século XIX, uma vez que esse princípio era a condição que legitimava a posse de territórios, em África. Tratou-se, basicamente, de contestações e disputas por áreas de influência entre Portugal e Inglaterra, despois de um conjunto de 
expedições levadas a cabo por Portugal e o seu ambicionso projeto do Mapa Cor-de-Rosa ${ }^{11}$. Em 1887, O governo inglês do Lord Salisbury dirigiu uma nota ao governo português, onde referia que:

Está agora admitido por todas as partes, nos termos da Ata de Berlim, que o direito de soberania na África só pode ser mantido pela real ocupação do território reclamado. Queira fazer um protesto formal contra toda e qualquer pretensão não fundada na ocupação e dirá que o governo de Sua Majestade [britânica] não pode reconhecer a soberania portuguesa nos territórios não ocupados por ele com força suficiente para manter a ordem, proteger os estrangeiros e fiscalizar os indígenas (PARENTE, 2004, p. 268).

Como forma de materializar o princípio de ocupação efetiva, Portugal levou a cabo um conjunto de expedições militares ${ }^{12}$, como objetivo central de "alargar a área de influência portuguesa para o interior da costa moçambicana, tentando obter, dos chefes indígenas locais, atos de vassalagem à Coroa Portuguesa" (SOUTO, 1995, p. 269). Diante destas incursões, surgem competições por ocupação e conflitos em áreas de interesse britânico. Essas disputas são resolvidas, em 1891, com a assinatura do Tratado entre Portugal e Inglaterra que, de acordo com Liesegang

Foi a peça mais importante num conjunto de tratados que definem as fronteiras de Moçambique, apesar de terem existido, anteriormente a ele, outros tratados que definiram partes de fronteiras e outros, posteriores, que modificaram alguns aspetos de detalhe a ele inerentes (LIESEGANG, 1993, p. 2-4).

Em termos gerais, o Tratado luso-anglofóno de 1891 é a base para a compreensão do processo de delimitação de fronteiras, em Moçambique. Todavia, este processo seguiu várias fases, envolvendo as regiões sul, centro e norte, com suas dinâmicas próprias. Por exemplo, "as disputas fronteiriças relativas às regiões sul e sul-ocidental foram resolvidas de forma relativamente mais rápida em relação a outras regiões do país (SOUTO, 1995, p. 269). As questões relacionadas com a delimitação da fronteira sul foram resolvidas, em 1872, quando

\footnotetext{
${ }^{11}$ Foi um projeto da Coroa Portuguesa com objetivo de unir Angola a Moçambique - Oceano Atlântico ao Índico - apresentado durante a Conferencia de Berlim, em 1884, mas que foi contestado pela Inglaterra devido aos seus interesses na região.

12 A Coroa Portuguesa organizou várias expedições militares: Expedição de Vitor Cordon à Machonalândia, em agosto de de 1988 a fevereiro de 1889 e a nova expedição em junho e outubro de 1889; Expedição de Paiva de Andrada a Gaza, de outubro a dezembro de 1888, e a Manica e Rodésia, de fevereiro a novembro de 1889; Expediação de António Maria Cardoso, entre novembro de 1888 e março de 1889; Expedição de Serpa Pinto ao Shire e Niassa, em agosto de 1889 e que foi continuada por João de Azevedo Coutinho.
} 
Portugal e Inglaterra concordaram em enviar à arbitragem do Presidente Francês a questão da posse de Lourenço Marques [atual Maputo - capital de Moçambique]. Esta arbitragem foi decidida pelo Presidente MacMahon, a 24 de Julho de 1875, a favor de Portugal. Em 1888, foi delimitada a fronteira, entre Moçambique e a Suazilândia, em relação à qual, a comissão formada chegou a um acordo com relativa facilidade, apesar dos protestos apresentados pelo Rei Swazi, contra a delimitação na cumeada dos Libombos (NEGÓCIOS EXTERNOS DE PORTUGAL, 1889, p. 56).

Este processo de mediação foi levado a cabo pela França e foi determinate para o estabelecimento da fronteira entre Moçambique a Suwazilândia, a chamada Fronteira de Namaacha. Trata-se de uma fronteira que separa o extremo sudoeste de Moçambique e estende-se no sentido norte-sul por $105 \mathrm{~km}$, entre duas fronteiras tríplices Suazilândia-Moçambique-África do Sul. A delimitação final da fronteira ocorreu na década de 1960, depois da proclamação da indepedência do Reino da Suazilândia, em 1968.

A tabela, abaixo, apresenta a sistematização dos principais tratados e acordos firmados entre as potências colonizadoras com territórios na região austral de África e que contribuíram para a firmação das fronteiras de Moçambique. Esses acordos permitiram a definição das linhas de fronteira da região sul, centro e norte, como se pode constatar no mapa cartográfico, abaixo.

\begin{tabular}{|c|l|c|}
\hline \multicolumn{2}{|c|}{ Tabela: 1 Principais Acordos e Tratados Estabelecidos Entre Portugal e } \\
Outras Potências Colonizadoras da África Austral
\end{tabular}




\begin{tabular}{|c|l|c|}
\hline 1886 & $\begin{array}{l}\text { Moçambique, onde Inglaterra reservou o } \\
\text { hinterland produtivo. }\end{array}$ & \\
\hline & $\begin{array}{l}\text { Assinatura do Tratado entre Portugal e } \\
\text { Alemanha para o estabelecimento do Rio }\end{array}$ & $\begin{array}{c}\text { Processo de } \\
\text { Delimitação da } \\
\text { Fronteira Norte de } \\
\text { Moçambique }\end{array}$ \\
\hline
\end{tabular}

Fonte: Souto (1995) e Garcia (2001)

O mapa 2, abaixo, apresenta os limites fronteiriços de Moçambique que resultaram dos processos de negociação e arbitragem francesa entre Portugal e Inglaterra, durante o Século XIX. Nele são apresentados os limites fronteiriços das regiões sul, central e norte de Moçambique, bem como a fronteira lacustre, no Lago Niassa, com a República do Maláui.

\section{Mapa 2: Linhas Fronteiriças de Moçambique}

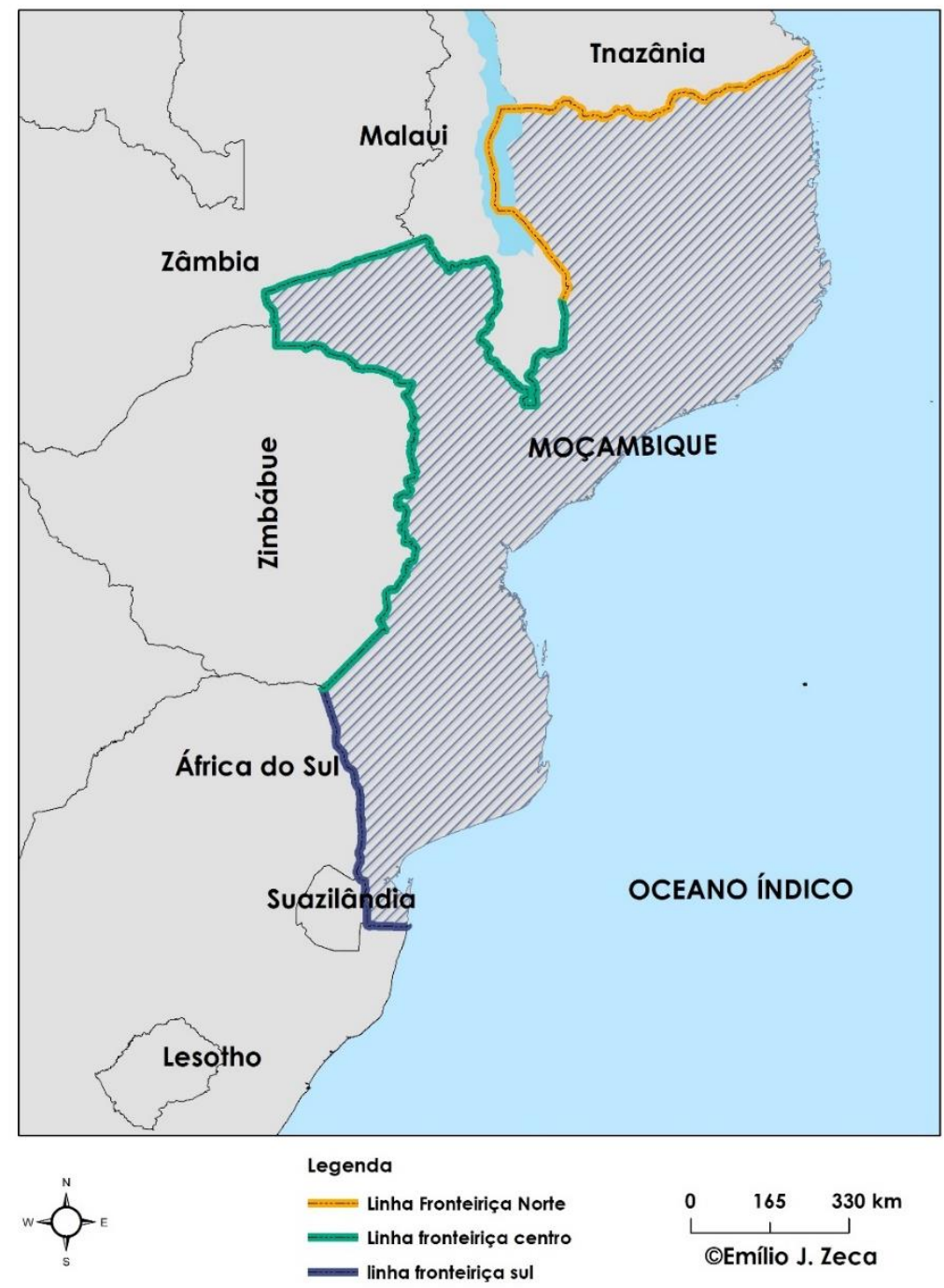

Fonte: Autor (2017). 
Em 1869, foi assinado o Tratado de Pretória, entre Portugal e a República Independete do Transvaal ${ }^{13}$, República da África Meridional - na atual África do Sul. Este tratado foi o primeiro a estabelecer os limites territoriais entre Moçambique e aquela república. $O$ tratatdo estipulava o seguinte:

O limite sul da Baía de Lourenço Marques atingia a latitude 26ํㅜㅇ de latitude, isto é, compreendia toda a Baía e continuava para o Oeste, até atingir os montes Libombos e seguindo a cadeia destes montes [a deliimitação de fronteiras acordada, em 1891, seguiu este tracejado] (SOUTO, 1995, p. 269).

A atual delimitação de fronteira entre Moçambique e África do Sul compreende dois trechos separados, num total de $491 \mathrm{Km}$ de extensão a leste da África do Sul. Estes marcos de fronteira têm um intervalo que comporta o território da Suazilândia, Estado que se situa entre Moçambique e África do Sul. A área norte desta fronteira inicia na tríplice fronteira África do Sul-MoçambiqueZimbábue e vai para o sul até a tríplice fronteira África do Sul - Suazilândia Moçambique, abarcado as províncias sulafricanas de Limpopo, a norte, e Mpumalanga, a sul, bem como a província de Gaza, em Moçambique. Uma parte da fronteira abarca o curso do Oceano Índico que segue ao norte do paralelo 27ํㅗ, separando as províncias de KwaZulu-Natal, na África do Sul, e Maputo, em Moçambique.

$\mathrm{Na}$ região centro de Moçambique - Província de Manica - e no Lago Niassa, "a questão de delimitação de fronteiras apresentou-se extreamente difícil e complexa" (SOUTO, 1995, p. 270). Tratou-se de uma zona de grandes disputas e conflitos, devido aos interesses conflituantes entre portugueses e ingleses. Portugal tinha desde cedo o seu plano do Mapa Cor-de-Rosa, mas os ingleses tinham a Bristh African Campany - BSAC ${ }^{14}$ cujo planos era atuar em grande

\footnotetext{
13 No século XIX, Transvaal representava os territórios da República Bôer - República Sulafricana, denominada de República do Transvaal. Era um território que ocupava a área Norte da atual África do Sul, entre a zona montante do Rio Vaal eo Rio Limpopo. Em 1902, a região foi anexada pelos britânicos e, em 1910, tornuu-se numa das províncias da África do Sul independente, juntando-se à Colônia do Cabo, formando assim a União Sulafricana.

${ }^{14}$ Foi uma Companhia Britânica criada por Cecil Rhodes, em 1889, fundindo a Central Gold Search Association e a Exploring Company, Ltd. para atuar na África Austral, nos moldes da Companhia Britânica das Índias Orientais. A companhia foi aprovada pela Cora Britânica e tinha privilégios majestáticos. O objetivo central da mes ma era de operacionalizar o proces so de colonização britânica, através da exploração económica da região - sobretudo o Zimbabwe - dentro dos princípio da ocupação efetiva emanado da Conferência de Berlim, procurando unir as operações coloniais britânica do Cairo ao Cabo. A Companhia cessões as suas funções depois de ser absorvida, em 1965, pelo Complexo Mineral Industrial chamado Anglo American PLC (BURNHAM, 1926 e RASMUSSEN e RUBERT, 1990).
} 
parte desta área, sobretudo a região de Manica e Zimbábue. Esse conflito atingiu a sua escalada, em 1988, quando começaram as expedições militares portuguesas para ocupação de territórios no interior de Moçambique, como fora referido, anteriormente. A expedição de Serpa Pinto a região do Shire e ao Niassa, em agosto de 1889, proporcionou uma reação militar da Inglarerra que apresentou um Ultimato, no dia 11 de Janeiro de $1890^{15}$, insentivando de forma pereemptória o governo português a chamar de imediato todas as suas tropas militares que se encontravam na região de Shire, Makololo ${ }^{16}$ e Mashona.

Diante do ultimato militar britânico, Portugal tinha duas alternaticas: "ou recuava para o sul do Rio Ruo, ou se dava a rutura e estalava-se o conflito armado entre os dois Estados" (SOUTO, 1995, p. 270) que eram aliados, desde as velhas guerras na Europa. Todavia, diante do poderio militar inglês, Portugal foi obrigado a ceder e retitou as suas tropas. O ultimato inglês abalou as pretenções ocupacionistas de Portugal, na região, e pressionou a Cora Portuguesa a iniciar conversações com Inglaterra, para a delimitação de fronteiras no Niassa e Manica.

No dia 20 de Agosto de 1890, foi assinado um acordo entre Portugal e Inglaterra onde

As cedências portuguesas eram grandes, porque além da delimitação das fronteiras, Portugal fazia concessões a nível de completa liberdade de comércio; livre navegação nos lagos, rios e portos; isenção de impostos aduaneiros nas zonas de livre comércio; isenção de taxas de trásito de mercadorias e pessoas, entre outros (AXELSON, 1967, p. 259).

Quando os termos do acordo foram divulgados, a imprensa portuguesa reagiu apontando que Portugal tinha sido humilhado pela Inglaterra com o acordo

\footnotetext{
${ }^{15}$ O Governo de Sua Majestade [Inglaterra] dirigido pelo Lord Salisbury dirigiu uma nota ao seu ministro em Lisboa para ser transmitisse ao governo português o seguinte: "que se enviem ao Governador de Moçambique instruções telegráficas imediatas para que todas e quaisquer forças militares portuguesas atualmente no Shire e nos países dos Macololos e Machonas se retirem. O Governo de Sua Majestade [britânica] entende que sem isto as seguranças dadas pelo Governo Português são ilusórias. Mr. Petre verse-á obrigado, à vista das suas instruções, a deixar imediatamente Lisboa com todos os membros da sua delegação, se uma resposta satisfatória à precedente intimação não for por ele recebida esta tarde; e o navio de Sua Majestade Enchantress (britânica) estará em Vigo, esperando as suas ordens"(PARENTE, 2004, p. 270).

${ }^{16}$ Era uma das tribo da região do Alto Zambeze que pertenciam ao grupo dos sotho da África do Sul e com semelhanças dos basotho do Lesoto. Esta tribo foi obrigada a deixar a região e migrar-se em direção ao Vale do Zambeze e Malaui, devido a expansão do Reino de Tshaka Zulu, durante o período do Mfecane (PHIRI, 2005, p. 851- 852 e GANN e DUIGNAN, 1999, p. 413-414).
} 
e com o ultimato militar. Alguns textos da época chegaram mesmo a afirmar que era melhor que "Portugal tivesse vendido Moçambique interiro [a Inglaterra], a conservá-lo sob tão vergonhosas condições" (AXELSON, 1967, p. 318). Diante desta situação, a Corte Portuguesa recursou ratificar o tratado, criando outras situações de animosidade, tensão e crise entre os dois Estados.

Com a decisão, acima referida, Portugal cometeu um erro estratégico, porque, primeiro não tinha capacidades militares para fazer face ao exercítio britânico, em situação de confronto militar e, segundo, a não ratificação do acordo dava uma espécie de carta-branca as forças militares de Cecil Rhodes para invadir a região de Manica. Apercebendo-se do erro estratégico, Portugal prôpos que Inglaterra assinasse um "Modus Vivendi" que "iria vigorar durante as discussões de um novo tratado" (SOUTO, 1995, p. 271). Tratava-se de uma forma de estabeler uma situação de coexistênia pacífica e não invasão de territórios. Esta proposta de Portugal foi aceite e, no dia 14 de Novembro de 1890, foi assinado o "Modus Vivendi" que reconhecia, provisoriamente, as fronteiras estabelecidas no Tratado de 20 de Agosto de 1890 e que o mesmo iria vigorar durante seis meses.

As negociações do novo acordo entre Portugal e Inglaterra foram dificéis e longas, porque Portugal encontrava-se numa situação de desvantagem. No dia 28 de Maio de 1891, foi assinado o Projeto de Convenção que

\section{Cedia a Portugal mais territórios a Norte do Rio Zambeze do que fora pedido, mas a sul do Zambeze, a linha corria ao longo da parte superior do declive oriental do Planalto de Manica, em direção ao sul até ao Save [retirando assum mais território a Moçambique que o tratado de 1891] (SOUTO, 1995, p. 271).}

Diante deste novo status quo, Portugal perdeu território em detrimento da Inglaterra, para a região que atualemente é o Zimbábue. O tratado foi ratificado no dia 11 de Junho de 1891 e criou condições para a estabilidade nas relações entre Portugal e Inglaterra, durante toda a metade do Século XX. Importa referir que o processo de delimitação fronteiriça com Malaui somente foi selado no dia 18 de Novembro de 1954, depois da firmação do último acordo de fronteiras entre Portugal e a Federação das Rodésias - atual Zâmbia e Zimbábue - e Niassalândia - atual Malaui, e Inglaterra, sobre a fronteira entre Moçambique e o atual Malaui, onde foi definido que a mesma passaria pelo meio do Lago 
Niassa. Portanto, durante estes acordos, recorreu-se à mediações e arbitragens para definir as fronteiras com Zimbábue ${ }^{17}$, Zâmbia ${ }^{18}$, Malaui e Tanzânia ${ }^{19}$.

\section{Desafios da Reafirmação das Fronteiras}

Com a proclamação da sua independência nacional, em Junho de 1975, Moçambique passou a conviver no sistema internacional com uma nova configuração dos seus limites e fronteiras que tomaram contornos de um Estado independente. Não obstante aos esforços de celebrar acordos com Estados vizinhos para a confirmação das fronteiras coloniais e seguir o princípio da União Africana de intangibilidade das fronteiras coloniais, nem sempre isso foi pacífico, porque "quando existe interesses econômicos [recursos ou posião estratégica] e geopolíticos [expansão territorial], a definição clara dos limites e fronteiras impõe-se e a falta ou excesso de zelo por questões de fronteiras é fonte de muitos confitos e dissabores" (MARTIN, 1997, p. 83).

Moçambique é um Estado que partilha por volta de 4212 quilómetros de fronteiras, onde 2685 quilómetros são terrestre, 1203 quilómetro de fronteira fluvial e 322 quilómetros de fronteira lacustre. Para além disso, o Estado possui

\footnotetext{
${ }^{17}$ A atual fronteira entre Moçambique e o Zimbábue é de $1231 \mathrm{~km}$ de extensão, indo do norte do Zimbábue para o leste de Moçambique, e daí para o sul. No norte, há uma tríplice fronteira Zimbábue-MoçambiqueZâmbia, por onde passa o Rio Zambeze e no sul, outra tríplice fronteira entre Á frica do Sul - Moçambique e Zimbábue, com uma parte da linha limítrofe a seguir Paralelo $16^{\circ} \mathrm{S}$. A fronteira separa as províncias zimbábuenas de Mashonaland Central, Mashonaland Este, Manicaland, Masvingo e as de Tete, Sofala, Manica e Gaza, em Moçambique. Esta fronteira foi firmada, em 1951, quando Moçambique tournou-se uma Província do Ultramar de Portugal.

18 A atual fronteira entre Moçambique e Zâmbia é de 419 km de extensão, no sentido Leste-Oeste, com a Província de Tete separando o leste do sul de Zâmbia e Moçambique. Neste pontou, a leste, há uma tríplice fronteira Moçambique-Zâmbia-Malaui e outra tríplice fronteira a oeste, onde passa o Rio Zambeze, entre Moçambique-Malaui-Zâmbia. A oficialização desta fronteira ocorreu com a proclamação da independência de Moçambique, em 1975. A atual fronteira entre Malaui e Moçambique é de $1569 \mathrm{~km}$ e começa na tríplice fronteira Moçambique-Malaui-Zâmbia, no Planalto de Angónia e segue muito irregular para sule sudeste, onde faz uma inflexão para norte, passando por Milange, margem oriental do Lago Chilwa e do Lago Chinta. A fronteira termina à margem oriental do Lago Niassa, onde termina. O Lago Niassa possui uma área de cerca de $31 \mathrm{mil} \mathrm{Km}$ quadrados, dos quais 6.400 fazem parte do território moçambicano, de acordo com o Acordo de 18 de Novembro de 1954, entre Portugal, Federação das Rodésias e Niassalândia e Inglaterra.

19 A atual temos a fronteira com Tanzânia que é de $756 \mathrm{Km}$. Esta fronteira começa às margens do Lago Niassa e segue em direção Oeste-Leste, passando pelas Montanhas Livingstone, seguindo o curso do Rio Rovuma até terminar no Oceano Índico, a Norte da Província de Cabo Delgado. Trata-se de "uma das fronteiras mais antigas" (NEWITT, 1995, p. 167) definida no período da Capitania de Mombaça - Colônia Alemã de Tanganica - em 1593, que fazia limite com a Capitania de Sofala - Colônia Português de Moçambique - através de Cabo Delgado. Essa é a base dos limites fronteiriços atuais, na região norte de Moçambique.
} 
uma costa marítima com cerca de 2700 quilómetros de extensão, onde partilha fronteira com "llhas Comores, Tanzânia, llhas da França e África do Sul". (JAMINE, 2007, p. 24). Dentre estes Estados, somente Tanzânia tem um acordo que define a fronteira marítima comum com Moçambique. Desde 1975, em vários pontos, os limites e fronteiras moçambicanas continuam indifinidas, porque muitos marcos fronteiriços foram movimentados ou destruídos por ação da naturaza ou antropomórficas mesmo. Isso acontece, poque "as fronteiras tem um caráter resistente, mas não imutável" (MARTIN, 1997, p. 82).

Para lidar com estes questões de fronteiras, através do Decreto 18/2001 de 3 de junho, foi extinta a então Comissão Interministerial de Fronteiras, criada em 1997, e foi criado o Instituto Nacional de Mar e Fronteiras, subordinado ao Ministério dos Negócios Estrangeiros e Cooperação, com o objetivo central de acessorar o Estado em questões relacioandas com a questões fronteiriças e direito do mar. Esta instituição surge num contexto importante, porque há ainda muitas silutações de falta de delimitação definitiva ou reafirmação de fronteira, sobretudo com Zimbábue e Malaui - fronteiras terrestes - com Comores, África do Sul, Madagáscar Tanzânia e França - fronteiras marítimas.

As fronteiras marítimas moçambicanas - com Madagáscar, África do Sul, Comores e França "não estão ainda delimitadas, porque não aconteceu o mesmo que aconteceu com as fronteiras continentais que foram delimitadas pelas potências coloniais" (CHISSANO, 2008), na Conferência de Berlim e outros tratados de fronteira subsequentes que foram apresentados no início deste estudo. Neste contexto, as principais disputas de fronteiras tanto terrestres quanto maríticas e fluviais das quais Moçambique está envolvido, recentemente, tem que ver com a questão de ocorrência de recursos marinhos e estratégicos como gás natural e petróleo. Para as fronteiras marítimas, as disputas centra-se na questão da expansão das plataformas continentais e atividades de pesca.

Para o caso da fronteira com Malaui ${ }^{20}$, a disputa centra-se, sobretudo, no Lago Niassa onde este Estado ocupa ilhas que a luz do acordo luso-britânico de

\footnotetext{
20 Malaui é o Estado que mais problema apresenta e desafia a delimitação, reafirmação ou fiscalização de fronteiras para Moçambique. Sempre apresentou divergências na interpretação dos acordos e pouco disponibilidade apresentou na alocação de recursos humanos e materiais para levar a cabo o processo, como indica a União Africana. Em contra partida, o processo reafirmação da fronteira com Zâmbia, Zimbábue e Tanzânia correu bem desde 2012 (AIM, 2012).
} 
11 de junho de 1891, fazem parte de Moçambique. Neste lago, também, está em causa algumas ilhas e locais onde há potencial para ocorrência de recursos estratégicos - petróleo e gás natural. Na parte da fronteira terrestre, está em causa as pretenções de expasão territorial daquele Estado. Estas disputas tem como pano de fundo "a ausência ou a fraca gestão da gestão, delimitação, demarcação e caracterização das fronteiras entre os Estados" (CHISSANO, 2008), o que faz com que os limites fronteiriços sejam aleatórios ou de acordo com as necessidades e interesses em jogo.

Portanto, diante deste quadro, para fazer face à esta situação, uma das alternativas é o recurso à gestão dos limites e fronteiras por meio de comissões conjuntas de especialistas em questões de fronteira. Estas comissões e especialiastas devem garantir a monitoria e aplicação dos acordos já firmados, bem como levar a cabo processos de delimitação de limites e fronteiras ainda não estabelecidos. Em todo esse processo, o recurso a situações de mediação e arbitragem deve ser a via recomendada como forma de solução de eventuais problemas fronteiriços de difícil interpretação e solução pacífica.

\section{Considerações Finais}

Os conflitos de delimitação, reafimação e fiscalização de fronteira tem como base central interesses económicos na região, expansão territorial e das plataformas continentais. Tendo em conta os princípios das organizações internacionais das quais Moçambique faz parte, a resolução destas disputas somente pode ser feita por via pacífica com recurso, por um lado das comissões de trabalho conjunto para delimitação e reafirmação das fronteiras ou, por outro, através da mediação e artibragem juntos dos tribunais fronteiriços internacionais, uma vez que os processos de delimitação de fronteiras e resolução de disputas fronteiriças envolve situações diplomáticas.

O processo de delimitação de limites e fronteiras nacionais moçambicana tem suas origens no período colonial. Não obstante ao fato do Estado moçambicano ter alcançado sua independência em 1975, ainda existem vários pontos onde a delimitação fronteirira ainda não é definitiva, abrindo espaço para conflitos e disputas com os Estados vizinhos. Sabe-se que os limites e fronteiras de um Estado têm relação direta com o seu exercício político e soberano. Desta 
feita, os problemas de delimitação de fronteiras fragilizam a soberania do Estado moçambicano. Desta feita, é importante que se leve a cabo o processo de delimitação, reafirmação e fiscalização de limites e fronteiras, com os Estados fronteiriços, apesar de ser uma questão sensível e que exigem sempre negociação.

A defesa da integridade territorial alcançada nos moldes dos antigos colonizadores tem que ser mantida. Desta feita, há que ter em conta a tentativas de ingerências dos Estado que fazem fronteira com Moçambique, com vista a que o respeito pela soberania e integridade territorial seja respeitado, porque as grandes ambições e os interesses destes estão sempre lá sempre presentes. Portanto, Moçambique tem que continuar com a abordagem de que o processo de delimitação, reafirmação e fiscalização de fronteira não deve ser levado a cabo de forma unilateral, uma vez que exige colaboração dos Estados e sua vontade explícita. Todavia, nem sempre é possível devido a fatores como interesses em jogo, capacidades, recursos, especialistas, entre outros.

\section{Referências Bibliográficas}

AlM - Agência de Informação de Moçambique. Mocambiquee Malawi Acertam Detalhes Sobre Fronteiras. Maputo: AlM, 13 de Junho de 2012.

AXELSON, Eric. Portugal and the Scramble for Africa 1875-1891. Johannesburg: Witwatersrand University Press, 1976.

BREYTENBACH, Willie. Democracy in the SADC Region: Comparative Overview. Institute for Security Studies. Africa Security Review. Volume 11, Number 4, PP: 87-102. Pretoria: ISS, 2002.

BURNHAM, Frederick Russell. Scouting on Two Continents. First Edition. Garden City N.Y: Doubleday Page \& company, 1926.

CARNEIRO, Camilo Pereira. Fronteiras Irmãs: Transfronteirizações na Bacia do Prata. Porto Alegre: Editora Ideograf, 2016.

CHISSANO, Miguel. Fronteira Mal Gerida é Porta Aberta a Conflitos. Entrevistas do Diretor do Instituto do Mar e Fronteira de Moçambique ao Jornal de Notícias. Maputo: Sociedade de Notícias de Moçambique, Segunda-Feira, 21 de janeiro de 2008.

GANN, Lewis H. e DUIGNAN, Peter. Africa and the World: An Introduction to the History of Sub-Saharan Africa from Antiquity to 1840. Lanham e Maryland: University Press of America, 1999.

JAMINE, ELíSIO. Delimitation of the Mozambique MaritimeBoundaries with Neighboring States (Including the Extended Continental Shelf) and the Management of Ocean Issues. United Nation Nippon Fellowship Programmed 2006-2007. Division for Ocean Affair and Law of the Sea. United Nations: New York, 2007.

JONES, Herlf. Atlas of World History. Second Edition. Herff Jones Nystrom: Indianopolis, 2012. 
LIESEGANG, Gerhard. História do Niassa 1600-1900: Estado, Política e Economia no Período Précolonial e a Conquista Colonial. Maputo: AHM, 1993.

MACHADO, Lia. Limites, Fronteiras e Redes. In Fronteiras e Espaço Global. Porto Alegre: AGB, 1998.

MARTIN, André. Fronteiras e Nações. 2ª Edição. São Paulo: Contexto. 1997.

NEGÓCIOS EXTERNOS DE PORTUGAL. Limites Entre o Distrito de Lourenço Marques e o Território do Mussuate. Documentos Apresentados às Cortes na Sessão Legislativa de 1889 pelo Ministro e Secretário de Estado dos Negócios Estrangeiros.Lisboa: Imprensa Nacional e AHM, 1889.

NEWITT, M. D. D. A History of Mozambique. Indiana: Indiana University Press, 1995.

ORGANIZAÇÃO DA UNIDADE AFRICANA - OUA. Carta da Organização da Unidade Africana. Addis Ababa: OAU, 1963.

PARENTE, Regina da Conceição Alves. A Narrativa na Aula de História: Um Estudo com Alunos do $3^{\circ}$ Ciclo do Ensino Básico. Dissertação de Mestrado em Educação; Minho: Universidade do Minho, 2004.

PHIRI, Bizeck J. Lozi Kingdom and the Kololo. In: Shillington, Kevin. Encyclopedia of African History. Volume II. New York: Routledge, 2005.

RASMUSSEN, R. K. e RUBERT, S. C. A Historical Dictionary of Zimbabwe. Metuchen. New Jersey: Scarecrow Press, 1990.

RATZEL, Friederich. O Solo, a Sociedade e o Estado. Revista do Departamento de Geografia da USP, Vol. 02, p. 93-101, 1983.

ROSIĖRE, Stéphane. Géographie Politique et Géopolitique: Une Grammaire de L'Espace Politique. Paris: Elipses, 2007.

SOUTO, Amélia Neves. Guia Bibliográfico Para Estudantes de História de Moçambique. Coleção Nosso Chão № 06. Maputo: Centro de Estudos Africanos, 1995.

UNIÃO AFRICANA - UA. Ato Constitutivo da União Africana. Lomé - Togo: UA, 2000.

ZECA, Emílio Jovando. Relações Internacionais: Natureza, Paradigmas e Assuntos Transversais. Maputo: Plural Editores, 2013.

Recebido em 18 de agosto de 2017. Aprovado em 09 de dezembro de 2017. 